\title{
DEMOCRACIA Y CULTURA DE MASAS (LA ENCRUCIJADA ÉTICO-POLÍTICA DE MILL, TOCQUEVILLE Y WEBER)
}

$\mathrm{P}$ or su carácter de libro de confrontación con aquel poder tan largamente establecido, considero a Estado de derecho y sociedad democrática (1966) no sólo el libro que más me influyó, sino el más admirable de Elías Díaz. A la última generación antifranquista, a la que pertenezco, recién llegados a una Facultad de Derecho, dividida para el pensamiento político académico entre Easton y el derecho constitucional comparado, este libro nos indicaba no sólo el pasado del Estado de Derecho sino el marco jurídico-político de nuestra futura democracia. En aquel controvertido período era tan convincente que apartó a algún que otro prochino del clarividente vaticinio de que nuestro país caminase indefectiblemente hacia una república arrocera, versión levantina, como la descrita por diferentes testimonios en otro libro también muy leído entonces, Una aldea de la China Popular. Esta tarea de diferenciación analítica entre la sociedad democrática y la aldea, entonces, no era gratuita para casi nadie. El mismo año que Macpherson manifestaba, en La realidad democrática, que existían modelos no liberales -comunista y tercermundista- de democracia, Elías Díaz clamaba porque a nosotros, injustamente, no nos correspondiese realidad democrática alguna. Su planteamiento fue clave en mi interés por una perspectiva historiográfica para afrontar los problemas filosófico políticos. Aquí traigo uno a revisión, cuya elección quizás inconscientemente también le deba: la tensión entre liberalismo, democracia y socialismo en el papel jugado por las élites decimonónicas en la construcción de las instituciones representativas. Una visión sobre el pasado puede servir de lupa de aumento para observar los problemas de la política actual. Ojalá mi análisis reflejara parecida capacidad de debate que De la maldad estatal y la soberanía popular (1984), al retomar aquí algunos de sus problemas e inspiraciones: Marx, Weber y la Escuela de Frankfurt.

Mill, Tocqueville y Weber realizan la cartografía de las instituciones 
representativas en un período paradigmático de convulsiones sociales: los sucesos franceses de 1848-1851 y las agitaciones sociales de la República de Weimar, desarrollada entre 1919 y 1933, enfrentan a demócratas, liberales, fascistas y socialistas. Aquellos tres son los artífices de una política reformista sustentada en la burguesía y en cuyas antípodas los dos primeros tienen como coetáneos a Marx y a Engels, y el último a Rosa Luxemburgo. Marx, por su parte, escribe desde el exilio londinense de pensador nómada sus textos historiográficos, desbrozando un amanecer revolucionario que premie el insomnio padecido por el cuarto estado. En La lucha de clases en Francia de 1848 a 1850 (1895) fija el momento de la revolución en la contradicción entre las modernas fuerzas productivas y las formas burguesas de producción. Marx sitúa todos los episodios de 1848 y 1849 bajo la divisa de la derrota de la revolución. Largo calvario le haría falta al partido de la subversión para sobreponerse a una contrarrevolución cerrada y potente. De forma más concluyente, Engels en el prólogo a esta obra -frente a la posterior opinión del espartaquismo alemánseñala como causas del fracaso de la insurrección del 48 el adelanto de las revueltas respecto al necesario acaecimiento de una crisis económica mundial y una mayor experiencia del ejército en la lucha callejera para aplacar las algaradas del pueblo. Engels acaba prefiriendo la utilización estratégica de los instrumentos electorales legales a las movilizaciones sociales. Con escala de valores opuesta, Tocqueville observa armado, frente a «la pura canalla de la insurrección», la «confusión fraterna sin desorden» de las fiestas revolucionarias en los Campos de Marte, y describe la revolución en sus Recuerdos, sin populismo alguno. La degradación de las costumbres públicas y la indignidad de los políticos para mantener el poder caldea el viento de revolución. Mill coincidió con Tocqueville en ver en el empobrecimiento de la «vida pública» la causa ecuánime de la caída de Luis-Felipe. Marx busca la explicación económica de la política; Tocqueville y Mill, en cambio, la otorgan su sustantividad propia. Mientras Mill y Tocqueville priorizan las libertades formales para el futuro de la política, Marx no aprecia cambio político que no deba concluir en una liberación real (Raymond Aron: 1967, 1965). Ambas posiciones reflejan la tensión entre una política revolucionaria y otra reformista -a veces crítica- que, hoy, heredamos decidida.

John Stuart Mill es clave para la reconstrucción del debate histórico entre liberalismo, democracia y socialismo en la política moderna del siglo XIX. Mill, Tocqueville y Weber están unidos por la fascinación por la cultura política anglosajona -siempre diferenciada de la del viejo continente- que surge con una novedad inaudita en Estados Unidos. En este vector teórico, Mill es un auténtico gozne 
en la reconstrucción de la teoría del liderazgo político de Alexis de Tocqueville y Max Weber. El «aire de familia» filosófico política que les asemeja se evidencia en ciertos rasgos compartidos por estas dos generaciones. En primer lugar, Mill escribió un espléndido comentario a La Democracia en América $(1835,1840)$ en la London and Westminster Review coincidiendo con su sucesiva aparición. Allí, subrayó la importancia fundamental atribuida por Tocqueville a la actividad política realizada en el ámbito de la vida local. Pero tanto en este comentario como en la correspondencia entre ambos quedó patente el papel fundamental de las élites democráticas en el poder representativo del gobierno democrático americano. Además, Weber leyó a Mill y citó al escritor inglés en «La ciencia como vocación» (1919), con rasgos sumamente problemáticos de distanciamiento y de coincidencia fundamental: un precedente al que está lejos de alabar y otorgar razón, pero al que reconoce el valor ontológico del politeísmo en cuanto se sale de la pura empiria. En segundo lugar, por su vinculación con el modelo desarrollista de democracia, Mill y Tocqueville conciben la política como instrumento de desarrollo espiritual e intelectual de los individuos. Sin embargo, tendrán que reflexionar frente a una antropología liberal precedente -el individuo maximizador de utilidades- que niega su modelo normativo de autorrespeto y perfección espiritual y se adapta mejor a la descripción del comportamiento individual moderno. Consecutivamente, Weber representa una propuesta política in extremis de aceptación de la perversidad del mundo y moralización de la vida política a través de la hercúlea tarea de un individuo carismático de cualidades heroicas. Mill conectó también con esta ética de la excelencia moral a través de Carlyle y Tocqueville por vía de Plutarco. En tercer lugar, los tres comparten la preocupación crítica frente a la conversión degradante de la política en una actividad rutinaria. Los tres observan críticamente la grave homogeneización propiciada por el mundo moderno y propugnan una dirección política del aparato burocrático. Ninguno de ellos acude a una fundamentación del poder en universales morales. A Weber nada le parecía más execrable que utilizar la ética para llevar razón, Tocqueville obvia las discusiones acerca de los principios generales en el día a día de la política, y a Mill le preocupaba poco si la propiedad era un derecho natural o no a la hora de reconocer límites variables a este derecho. El politeísmo moral de Weber ya está presente en Mill, quien comparte con Tocqueville una teoría moral basada en la libertad. La explicación de todos ellos del poder es estratégica y no reducible al lenguaje de los derechos universales.

Desde tradiciones culturales muy distintas, los tres subrayan los males endémicos del proceso de racionalización del mundo moderno bajo las formas de centralización, organización racionalizadora, 
reducción de la vida a supervivencia o elusión del deseo al cálculo administrado. Tanto Tocqueville como Mill y Weber sitúan la acción social moderna bajo el dictum de Adorno y Horkheimer de crítica del contenido represivo de la igualdad: «el precio de la igualdad de todo con todo consiste en que nada puede ser idéntico a sí mismo. La ilustración disuelve el error de la vieja desigualdad pero [...] destruye lo inconmensurable. [...]». La constricción moderna de la libertad en el interior de la weberiana «jaula de hierro» es debelada de la misma crítica forma en el frankfurtiano viaje de Odiseo. La mayor cientificidad y eficiencia de la máquina administrativa genera menos libertad. Nadie escapa a este poder acrecido del Gobierno moderno que, cuanto más se expande, más puede prescindir de las demandas sociales. Si el postulado reformador de Bentham era todavía organizar y moralizar la administración racionalmente, la preocupación de Mill y Tocqueville es evitar su sobredimensionamiento. Ambos comparten la misma concepción de la libertad. Tocqueville le escribe a Mill en una de las últimas cartas: «Mi querido Mill, recibí ayer su libro Sobre la libertad. Me lo he encontrado en Cannes, donde mi salud me forzó a venir para pasar el invierno. [...] siento indudablemente a cada instante que sobre este terreno de la libertad no sabríamos marchar sin darnos la mano» (9 de febrero de 1859). Mill, influido por Tocqueville, temió los efectos homogeneizadores de aquel criterio en que Bentham fijó máximas esperanzas: el control político y moral de la «opinión pública». La tiranía de la opinión mayoritaria supondría necesariamente una opresiva limitación del alma individual. De ahí que los rasgos más sobresalientes de la filosofía moral de Sobre la libertad (1859) repare en la protección de la disidencia, el ideal del desarrollo de la individualidad no sometido al yugo social, la libertad de creación y expresión de una opinión incluso herética, $y$, en definitiva, la inexistencia de otro criterio de intervención estatal en la esfera de libertad civil y política que evitar un daño a terceros.

Del temor a la reducción absoluta de la política a administración surge el compromiso teórico y práctico de Tocqueville, Mill y Weber por una organización dinámica del monstruo burocrático. Para Aron, el problema central de Tocqueville es el desarrollo de uno de los problemas que plantea Montesquieu: el despotismo o poder arbitrario de uno sólo es contrario a la libertad, mientras que una república o una monarquía moderada pueden proteger la libertad. Para Montesquieu, la desigualdad es garantía de libertad en la monarquía francesa. Pero al estudiar la monarquía inglesa, se encuentra con una monarquía liberal, basada en la representación y la primacía de la actividad mercantil. Tocqueville desarrolla los análisis de Montesquieu sobre la monarquía inglesa, consciente de que aquí la libertad -a diferencia de lo que ocurría con la monarquía francesa- no requiere de desigualdad 
de condiciones (Raymond Aron: 1967). Pero Tocqueville experimenta en carne propia cómo la aristocracia es un Gobierno indefectiblemente superado. Tal como señala Schmitt, Tocqueville es el pintor y moralista de una época que vive existencialmente como vencido. Su coraje intelectual y cortesía se sobrepone sobre una ruidosa desesperación (Carl Schmitt: 1950). Se desinteresa por viajar a Inglaterra porque los gobiernos mixtos le parecen sociológica e históricamente superados. Respecto de Francia, la experiencia americana reúne la ventaja de surgir sin revolución. En comparación con Inglaterra, a la que secunda, América aporta incluso una democracia en estado puro. Los ingleses son aristócratas en Inglaterra y demócratas en Estados Unidos (François Furet: 1984). Tocqueville abre así una firme inquietud por la vida norteamericana proseguida por Mill y Weber.

Frecuentemente, en la teoría social de Tocqueville se han resaltado aspectos de valedor de una sociedad autorregulada por un supuesto predominio absoluto de la vida política local. Sólo cuando la sociedad padece de desintegración surge un Estado centralizador y un individualismo egoísta, apropiado a la desaparición de los cuerpos intermedios. No se obvia la ineludible existencia de un poder externo, pero el acento final se pone en la capacidad de los hombres para autogobernarse. Tocqueville resultaría ser un anti-Hegel (Pierre Bimbaum: 1970). Sin embargo, la corrección de la, para él, inconveniente centralización administrativa confía que venga de un «arte» político que tuerza esta pésima tendencia de la sociedad moderna. Aunque el énfasis en la participación política descentralizada es cierto, Tocqueville otorga, siguiendo la tradición política clásica, un papel decisivo a la centralización gubernamental -de la que sí es partidario-, y al consiguiente liderazgo elitista, en la materialización de esta particular intervención política en la sociedad. Tan importante es la libertad de asociación, para Tocqueville, como la selección de élites y técnicos en el gobierno representativo. En una sociedad atomizada, las asociaciones contrapesan la débil presencia de las demandas individuales, inexistente en comparación con el paternalista peso del Estado. Pero existe una distancia manifiesta entre el origen de la soberanía democrática y su ejercicio efectivo en la democracia representativa. La vida pública está abierta a todos según diversos niveles adecuados a las diferentes aptitudes y capacidades. Más allá del gobierno local, la soberanía popular sólo interviene en la elección y control de los representantes (Jean-Claude Lamberti: 1983). La interpretación de Mill de La Democracia en América se basa en que existe aquí una «distinción capital entre delegación y representación». Además, ambos comparten idéntico pesimismo sobre los procesos de racionalización: el liderazgo político 
está bloqueado por la homogeneización moderna de los individuos y no es evidente que la democracia impulse la libertad de expresión. Pero Mill es dos puntos más optimista sobre las posibilidades de la democracia: no ve mal endógeno en la falta de cultura dirigente en Estados Unidos, cabe educarla en la «clase ociosa»; y atribuye el embelesamiento cultural por la prosperidad económica a la civilización y no a la democratización. En todo caso, ambos denunciaron la asimilación cortesana de los intelectuales al orden imperante y el rentable adocenamiento de la mayoría a la cultura de masas como mal endémico de la democracia emergente. «El hombre de genio se hace cada vez más raro -señala Tocquevilley la cultura más común». Y, a la vez celebraron la profundización del Gobierno popular, mayor garantía frente a los «intereses oscuros», afectos a la actividad política.

El proceso moderno de democratización de la política era así de ambivalente e ineluctable para ambos. Tocqueville sí es un antiMacintyre, pues piensa que la fragmentación que observa de la sociedad moderna es propia de la sacudida de un paradigma histórico -el premoderno- irremisiblemente superado. Más allá de cualquier «ironismo escolástico», muestra un esfuerzo sincero -inútil es añorar la caduca comunidad bien ordenada- por remontar los males que ya le parecen inevitables de la democracia: homogeneización normalizadora por el disfrute o aspiración al bienestar, pérdida de cualquier estima hacia el noble esfuerzo espiritual y, sobre todo, riesgo de «inmovilismo chino» entre los ciudadanos y de ejercicio de un «despotismo asiático» venido de las alturas. Destino común a Rusia y a Estados Unidos -para asombro de Schmitt, ya aisladas como las dos superpotencias futuras por Tocqueville. En un país como Estados Unidos, donde el acceso a las fortunas intermedias y su expansión está generalizado, el poder de las mayorías no se ejercerá sobre las riquezas de unos pocos sino sobre las opiniones disidentes y las minorías de raza y religión. Para Tocqueville, la terapia democrática consiste -y aquí coincide con Mill y Weber- en la profundización de la educación política a través de la revitalización del asociacionismo y el quebrantamiento de la opinión pública por las élites democráticas.

Tocqueville se atribuye la aceptación de la igualdad de condiciones -las naciones mantendrán indefectiblemente este estado- y se arroga la crítica de la servidumbre acarreada por la pérdida moderna de la virtuosa libertad aristocrática. Vislumbra que las condiciones sociales americanas -igualitarias por económicamente abundantes- son el futuro del viejo continente. Pero no hay que olvidar que es representante genuino del liberalismo -antisocialista y refractario al obrerismo, en Francia, a diferencia de Mill, en Inglaterra-, y reflexiona en el centro de convulsiones populares destructoras de los 
deficientes límites burgueses del contrato liberal. Su conservadurismo le impide reconocer este déficit de legitimación en la sociedad que irrumpe. Y, no obstante su virtualidad crítica, diagnostica que la desaparición de la sociedad aristocrática supuso la ausencia de sus fuertes virtudes, sin que el estado social democrático haya procurado aquello que pudiera aportar la igualdad social. La fuerza de la minoría fue sustituida por la debilidad de todos. Pero no cabe vuelta atrás en este movimiento moderno traído por la Providencia. El mayor obstáculo a la dinamización de la democracia es la hipostatización de un humanismo burgués que no reconoce otro movimiento que el aspirante a los pequeños negocios económicos. François Furet ha fijado, precisamente, la actualidad de Tocqueville en la manifiesta incompatibilidad entre bienestar y libertad que viene caracterizando a nuestro sistema democrático como deficitariamente legítimo. Ni la disidencia ni la participación vienen a coincidir con un pacto mayoritario en torno al bienestar igualitario (François Furet: 1991). Sobre el terreno, en Estados Unidos, Tocqueville le escribe a Chabrol: para la sociedad americana, «el interés es el único secreto. [...] Estamos aquí muy lejos de las repúblicas antiguas, ¿no es verdad? [...] Lo que conduce a los hombres a enturbiar al Estado es, por un lado, las ganas de conseguir el poder, de otro, la dificultad de formarse una existencia feliz por medios ordinarios. Aquí, en absoluto hay poder público y, hablando en serio, no hay necesidad de él» (10 de Junio de 1831). Y su amigo Gustave de Beaumont -con quien viaja a América y completa la descripción del costumbrismo americano- cuenta a su madre: «Vivimos en un país que no conoce en absoluto, desde hace mucho tiempo, las disensiones civiles y políticas. En verdad, no hay más que un partido en América; las disputas que se avivan en los periódicos o en la sociedad son más bien relativas a las personas que a las cosas. Hay que subrayar que los empleos públicos más elevados son poco buscados; aquí sólo hay una cosa que excita vivamente las ambiciones, es la riqueza. Solamente la fortuna da crédito, consideración, poder; los empleos públicos, que son poco retribuidos, no dan ni consideración, ni poder, ni crédito; por lo que no son solicitados más que por los que no tienen nada mejor que hacer. [...].» (Nueva York, 7 de junio de 1831). Pese a estas malas condiciones sociales -el interés particular aparece como el único móvil para la escasa pasión política-, Tocqueville quiere para su historiografía una función normativa. Frente al determinismo histórico de los historiadores en democracia -partidarios de la obediencia ciega e inflexible a los acontecimientos-, Tocqueville desea, a la manera antigua, enseñar a mandar. Considera que, en todo período político, las grandes personalidades políticas desarrollan la historia en un sentido o en otro. Gobernarse a sí mismo y gobernar a los otros rompe 
la inexorabilidad de las leyes generales de la historia. El mayor obstáculo democrático a este liderazgo político es el establecimiento de la «humanidad» en la mediocridad y el bienestar. El apagamiento de la juventud y la imaginación, la pérdida de cualquier extremo, el aislamiento de los disidentes y el debilitamiento cortesano de los mayores talentos son efectos de este nivelamiento social democrático. Tocqueville puede ser interpretado en clave de antihumanista y antiburgués.

La vida asociativa y una «doctrina del interés bien entendido» habrían de contribuir a la selección democrática de élites. Pero, aunque este sea el móvil último de su teoría política, Tocqueville observa en Estados Unidos un predominio vacío de la partitocracia en el poder sólo contrarrestrable a través de otras asociaciones. Una gran desconfianza popular hacia los grandes talentos y el servilismo de los elegibles respecto de los electores procuran un fracaso absoluto en la selección popular de élites: sólo el Senado, mediante un segundo grado de elección, propicia la honorabilidad de los debates parlamentarios americanos. Tocqueville atisba una crisis en el sistema americano de partidos -análisis proseguido por Bryce, Ostrogorski y Weber-, provocada por la proliferación de «pequenos partidos» que nunca representan el interés público y ahogan la actividad franca y audaz de los «grandes partidos»».

Tocqueville alentó en la primera parte de La Democracia en América un buen augurio sobre la descentralización administrativa americana y su impulso local. Cinco años más tarde, el acento último recae en el predominio de la weberiana dominación legal-racional, sin que haya determinado un resorte claro de selección de las élites culturales democráticas, fundamentalmente valoradas en su teoría política. El sentimiento igualitario tiene su correlato en la dominación democrática de un poder único y central y una legislación uniforme. El temor al desorden y el amor al bienestar favorecen el predominio absoluto del poder central en manifestaciones cada vez más amplias de la acción social. La destrucción final de todos los poderes secundarios consagra así el despotismo administrador y el predominio de un individualismo atomizado y políticamente estéril. Tocqueville concluye diciendo: «la igualdad sugería la noción de un gobierno único, uniforme y fuerte. Acabo de mostrar cómo también les habitúa a él; así que es hacia un Gobierno de ese tipo al que tienden las naciones en nuestros días. La inclinación natural de su espíritu y de su corazón a él les conducía y, para alcanzarlo, les basta con no ponerse límites. Creo que en la era democrática que se inicia, la independencia individual y las libertades locales serán siempre un producto del arte político. La centralización será la forma de gobierno natural.» (Alexis de Tocqueville: 1840). La segunda parte de 
La Democracia en América señala un giro hacia el reconocimiento del auge centralizador. En 1835 le había preocupado la concentración popular y legislativa del poder, ahora la creciente acumulación del poder del Estado y su burocracia (James T. Schleifer: 1980). Tocqueville ha oscilado entre el postulado de las grandes virtudes aristocráticas de Plutarco, la reivindicación del honor antiguo en las naciones modernas, y un pesimismo pascaliano sobre el futuro de la libertad en las sociedades democráticas (Luis Díez del Corral: 1989). La absolutización del consensus democrático es el único devenir real y horizonte individual en la historia. El «hombre democrático» desconoce que es más objeto que sujeto del proceso de igualación. Ante la absolutización de las virtudes morales universales, la libertad aparece como un don extraño al «hombre democrático» (Pierre Manent: 1993).

El postulado filosófico-político de Mill y Weber puede ser hoy interpretado como una terapia de urgencia a las aporías de la política moderna, no exenta de titubeos en su afirmación democrática. Weber sobrevaloró la democracia plebiscitaria sobre la democracia parlamentaria (Joaquín Abellán: 1992; Wolfgang J. Mommsem: 1959). De Mill no hay que olvidar que su compromiso socialista, querido como profundizador de la democracia (John Stuart Mill: 1873), y su obrerismo estuvo teñido por su teoría del voto plural, matiz de su sufragismo. Mill había percibido ya el posible éxito de la estrategia electoral del movimiento obrero propugnada por Marx y Engels: el auge de los trabajadores manuales concluiría en una legislación favorable a la clase trabajadora. De aquí que propugnara el favorecimiento numérico de los más preparados culturalmente, bajo la intención de favorecer la imparcialidad de las instituciones democráticas. No cabe reconstruir -tal como hace Berlinla filosofía política de Mill sobre las élites a través de Sobre la libertad (1859) sin aludir a Del gobierno representativo (1861). Es cierto que -tal como señala Berlin- Mill fue crítico corrosivo de la «religión sin teología» de Comte. No compartía ni su afán reglamentista, ni su deseo de imponer un altruismo perfecto sobre cualquier tendencia personal. La solidaridad querida por Mill no debería surgir de la paralización de las pasiones e inclinaciones egoístas por la fortificación habitual de las afecciones sociales. La descripción que Mill hace de la transición del anarquismo al positivismo puritano, prevista por Comte, es burlesca (John Stuart Mill: 1865). Pero del santsimonismo le hace un encarecido elogio a Gustavo d'Eichtal cuando aprueba la regeneración y desarrollo de la sociedad que está emprendiendo este movimiento «à la tête de la civilisation.» (30 de noviembre de 1831). De forma mucho mas precisa que Berlin, Macpherson resalta el temor de Mill a un gobierno de trabajadores. Finalmente, la 
predicción de Bentham y James Mill de que el sufragio universal no favorecería tal gobierno y la clase trabajadora seguiría el ejemplo de la clase media acabó confirmándose cuando, muerto Mill, se introdujo el sufragio universal de los varones (C. B. Macpherson: 1976). Más cercano al fourierismo que al comunismo, Mill objetaba al socialismo revolucionario su tendencia a estrangular la opinión minoritaria en aras de la decisión colectiva y a precipitar los necesariamente paulatinos cambios históricos (John Stuart Mill: 1979). Del gobierno representativo prioriza, claramente, el liderazgo de los más capaces e inteligentes y se opone a una posible legislación de clase (trabajadora). Pero su terapia al sedentarismo de las instituciones políticas modernas determina un paradigma reformador del que no hemos salido.

Mill fija en la selección de las élites la salida a los dos males de la política moderna: inexistencia de educación política y burocratización de las decisiones colectivas. La complejidad de la acción social determina en Mill -como en Weber- la disposición de las decisiones públicas por el aparato institucional. La determinación de las funciones del político y del funcionario delimita, tanto en uno como en otro, el ámbito de la imaginación de fines colectivos y de la ejecución de órdenes, respectivamente. Además conciben el Parlamento como el órgano deliberativo capaz de seleccionar a las élites. Así señala Mill, en expresión clave que Weber suscribiría: «La enfermedad que afecta a los Gobiernos burocráticos, y del que ordinariamente perecen, es la rutina. [...] se necesita un régimen popular para que las concepciones de los genios originales tengan probabilidades de prevalecer sobre el espíritu inerte y hostil de las medianías que no ignoran la tradición pero carecen de ciencia. [...].» Esta «glorificación del genio», como individuo activo y original, realizada por Mill, es un precedente de la noción moderna de carisma radicalizada por Nietzsche. Para Mill el genio posee una capacidad estimuladora de la inteligencia media de los individuos (Charles Lindholm: 1990). En cambio, en la formulación del genio realizada por Nietzsche, en Sobre el porvenir de nuestras escuelas (1872), el hombre superior surge en el sacrificio plurisecular de las capacidades de la medianía de la sociedad.

Pese a que la teoría de la personalidad y el politeísmo valorativo nietzscheano sean trasfondo de la teoría del liderazgo político weberiano (Wolfgang Mommsem: 1974), Weber no comparte esta concepción del sacrificio colectivo a la voluntad del líder. El líder carismático ha de impulsar el bien común o economía política de la nación alemana. Pero su concepción del carisma ha perdido la confianza de Mill en la capacidad desarrolladora del espíritu, procurada por el gobierno representativo. Weber hizo extensivo el sufragio al 
conjunto de la nación alemana, a través de su contribución personal en el artículo 41 de la Constitución de Weimar. Pero el liderazgo político weberiano supone una alternativa agónica al pesimismo de Tocqueville acerca de las posibilidades de superación de la centralización del poder y la universalización del cálculo individualista, Tocqueville y Weber compartieron la confianza en la iniciativa económica privada para sustituir las estructuras económicas tradicionales. Pero su reverso despotenciador del espacio público de la política no es lamentado por Weber, pues habrá de colmarse con la especificidad de la labor del político, definitivamente operada por la división social del trabajo. La Democracia en América plantea la tensión weberiana entre la dominación legal-racional y la dominación carismática. Superada irreversiblemente la dominación tradicional, los últimos restos de elementos carismáticos se encuentran en las virtudes nobles del ocaso social aristocrático. Para Tocqueville prevalecerá en el futuro un horizonte cerrado para la política activa cuya posible superación no vendrá determinada por la universal dinámica de la historia. Weber es heredero de esta aporía práctica sobre la que construye una teoría política definida por la teoría de la dominación, de la burocracia y del liderazgo. La definición weberiana del Estado y de la actividad política, ofrecida en «La política como vocación» (1919), no deja ningún margen a un modelo desarrollista de democracia: «[...]. Estado es aquella comunidad humana que, dentro de un determinado territorio (el «territorio» es elemento distintivo), reclama (con éxito) para sí el monopolio de la violencia física legítima. [...].» Weber se revela, en «Parlamento y Gobierno en una Alemania reorganizada. Una crítica política de la burocracia y de los partidos» (1918), como un representante de primer orden del modelo democrático competitivo de partidos: «[...] la esencia de toda política es luchar, ganarse aliados y seguidores voluntarios [...]», a lo que añade: «[...] para el liderazgo político, en todo caso, sólo están preparadas aquellas personas que han sido seleccionadas en la lucha política, porque la política es, en esencia, lucha. [...]». Aron en un importante artículo «-Max Weber et la politique de puissance» (1964)- analiza esta Machtpolitik que Weber reduce al ámbito del Parlamento $\mathrm{y}$, consecutivamente, a la liza internacional, atribuyéndola no supeditarse ni al derecho ni a una ética universal. Efectivamente, Weber, como descendiente de Maquiavelo y Nietzsche, no se pregunta qué régimen es justo: sitúa la lucha en el centro del papel que cada nación ha de ocupar en el ámbito internacional. Para Aron, el combate estipulado, por Weber, para la política entre naciones, clases o individuos se encarna tanto en el parlamentarismo como en el nacionalismo imperialista alemán. Aron subraya éste último como el auténtico demonio del sociólogo alemán que, unido a su confianza en el líder carismático, 
plebiscitariamente elegido, acabaría situándole en la pendiente del nazismo que hubiera deplorado. Para demostrar su tesis se limita a analizarla en el ámbito de las relaciones internacionales. Atribuye a Weber lo que corre, por su crítica del parlamentarismo, más rigurosamente por cuenta de Carl Schmitt. Weber sería así el artífice de una teoría sociológica singular y de una teoría política marcadamente atroz y caduca.

Pero, muy al contrario, su interpretación parlamentaria nos sitúa ante uno de los horizontes más dinamizantes de la política contemporánea. Una moralización de la vida política de alcance social, caracterizada por transformaciones profundas, la organización y la participación de base, auspiciada por el espartaquismo era, para Weber, una provocación a su persona y un desconocimiento vehemente de la responsabilidad del político. El ámbito más restringido de moralización weberiana de la política es el de los políticos profesionales. El gran obstáculo histórico de la política weberiana es la falta de liderazgo político en una nación vaciada de educación política por Bismarck, artífice de una política unipersonal movilizada por una corte de políticos que preservan el «monopolio de prebendas» y «patronazgo de cargos» (Max Weber: 1918). Weber confía en que la reforma del artículo nueve de la Constitución alemana posibilite la selección del Gobierno en el Parlamento: «[...] El objetivo de una parlamentarización es convertir al Parlamento en un lugar para seleccionar dirigentes. Y un dirigente político no aspira al cargo ni a un sueldo que le permita después una pensión ni tampoco al ejercicio de unas competencias lo más libremente posible, sin controles, sino que aspira a un ejercicio político, y esto quiere decir, a un poder responsable políticamente apoyado en la confianza y en la clientela de un partido, en cuya cúspide o en su centro debe desear permanecer, como ministro, para influir en él. [...].» (Max Weber: 1918). Sin esta dirección política, parlamentariamente seleccionada, no cabe gobierno de aquello que, para Tocqueville, por futuro político inevitable, requeriría del dominio de un auténtico arte político. Ambos ven un porvenir caracterizado por un dominio burocrático común a todo signo político. Tocqueville reparte su escasa confianza terapéutica en la influencia ejercida entre organizaciones horizontales y verticales; Mill y, sobre todo, Weber confían en una dirección vertical. En todo caso, no les caracterizó la confianza sino, más bien, la animadversión hacia las soluciones que les pudieran llegar de sus conciudadanos medios, bajo la fórmula, acuñada por Tocqueville, de «tiranía de las mayorías»».

En la República de Weimar, Weber -como Meinecke o Mann- se sitúa entre aquellos que vinieron en llamarse «republicanos de cabeza». Intelectuales que asumen la república fríamente, fruto de un 
compromiso cerebral, reflejo, todavía, de una tensión social entre aristocratismo irracional y democratismo racional. «El Estado nacional y la política económica» (1895) plantea una severa identificación de la clase social más apropiada al liderazgo económico político de la nación alemana, decidida, con dificultades, por la burguesía. En opinión de Weber, la clase dirigente habría de ser portadora de la conciencia económica de la nación. La tradicional aristocracia rural prusiana languidece y es pusilánime para representar a la economía política de la nación alemana. El proletariado carece de instinto nacional de poder y energía catilinaria de la acción. Las escasas esperanzas futuras de liderazgo de clase, Weber las sitúa en la burguesía a la que pertenece: "Yo soy un miembro de las clases burguesas, me siento como tal y he sido educado en sus principios e ideales. Pero el contenido de nuestra ciencia es, justamente, decir lo que no gusta oír -hacia arriba, hacia abajo y también a la propia clase-. Y cuando me pregunto si la burguesía de Alemania está hoy madura para convertirse en la clase política dirigente de la nación, no me es posible contestar, hoy por hoy, que sí. [...].» La reflexión política de Weber se dirigió, tras esta programática declaración, a la formación de una teoría política burguesa. El interés weberiano por preservar un ámbito de libertad de la depredación esclavizadora de la burocracia está inserto dentro de la preocupación burguesa por la libertad en el desarrollo capitalista de esa época (David Beetham: 1974). Weber guarda distancias con el carisma aristocrático que, vinculado con la democracia corporativa, abriría paso al nacional socialismo (Arthur Mitzman: 1969). Aunque sea cierto que la última fase del pensamiento político de Weber es plebiscitaria y no parlamentaria, su formulación de las cualidades del líder es, todavía hoy, la más ácida crítica de la supeditación de la política a meros fines técnicos (Antonio Valdecantos: 1992). La decisión personal creadora, encarnada en el líder, es decisión libre y racional entre fines metafísicos, no supeditados a las condiciones del medio, representadas por el técnico y el hombre de orden. A una vida social dominada por la racionalización y los sistemas burocráticos (José M. González: 1989), Weber opone la fuerza heroica del carisma, basada en una intransigencia de origen puritano (Wolfgang Mommsem: 1965).

Sin embargo, la terapia democrática weberiana no remontó el estancamiento de las instituciones de su época. La profesionalización no vocacional de la política, la confusión de funciones y responsabilidades políticas y funcionariales, la reducción de las asociaciones políticas a empresas que aprovechan los puestos de la Administración para premiar a sus partidarios, el predominio de la política de poder sin fin alguno, la disecación del Parlamento por la disciplina dictada por maquinarias burocráticas de los partidos supeditadas 
al líder caudillista o la trivialización sentimental del discurso y del debate político aparecieron como síntomas habituales de la fisiología democrática. La política de Weber acaba asemejándose a una política sustentada en el singular crédito moral del personaje que la postula (Karl Jaspers: 1920, 1932), mientras todo se derrumba a su alrededor. Ni la entrega apasionada a una causa, ni su orientación responsable, ni la mesura recogida y tranquila ante la decisión brillaron en la política reformista postulada por Weber. Y, sin embargo, se ocupa de regenerar la única política posible en nuestro horizonte futuro. $\mathrm{Su}$ antípoda política fue el ideario espartaquista de Rosa Luxemburgo, reflejado en Huelga de masas, partido y sindicatos (1906). Una emocionada apuesta por la prioridad de la valerosa acción obrera de base sobre la organización, en la huelga de masas, que quería convertir a la revolución rusa en parte de la historia social y política de los obreros alemanes. Pero, según Weber, las organizaciones sindicales, de las que era partidario, se perpetuarían en un modelo capitalista. Además, la revolución socialista no traería una destrucción del aparato burocrático sino su reforzamiento. En tanta emoción, Weber sólo veía una intoxicante ilusión de transformación radical de la sociedad: «Liebknecht -dijo- debía estar en un manicomio y Rosa Luxemburgo en un zoológico.» (Anthony Giddens: 1972).

«El socialismo» (1918) revoca, ya entonces, tres de los presupuestos fundamentales que habían diferenciado a la política marxista. La democracia sólo significará, en el futuro, según el canon liberal, inexistencia de desigualdades formales en los derechos políticos de la población. Las leyes de la historia no caminan indefectiblemente, como señalaba la profecía, al advenimiento de la sociedad sin clases. La separación del trabajador de los medios de producción es efecto de la complejidad de la vida productiva y no medio de explotación. Aún no satisfaciendo todas las preferencias políticas, el horizonte de la política contemporánea, el nuestro, es weberiano. Pero es difícil opinar que aquellos problemas que, in nuce, diagnosticaron Mill, Tocqueville y Weber hayan sido superados. Todos ellos no pensaron en criterios regulativos que orientaran la vida social, sino en impregnar a todas las instituciones sociales y a los individuos de una dinamización política que no predominaba entonces ni predomina ahora. Hoy el pesimismo que les caracterizó adquiere rango de patetismo. El mayor cambio habido en la política representativa contemporánea sobre la debilidad originaria de la imperiosa educación política y la selección de las élites, característicos de aquel paradigma moderno, es del orden del salto de la cantidad a la calidad: aquel predominio de la cultura de masas se expandió en la hegemonía absoluta de la «sociedad del espectáculo» y de la adoración al 
Becerro de Oro. Del compromiso intelectual y moral de aquellos gigantes ya desaparecidos no me cabe duda. De la urgencia de la reflexión acerca de los dilemas que abrieron, ni resquicio. Elías Díaz ha seguido una dilatada dedicación, fructífera y sugerente, a la problematización de las desigualdades económicas en los gobiernos democráticos. A todos nos corresponde -incluido, desde luego, el joven Elías Díaz- la prosecución de esta reflexión, antes de que tengamos que preguntarle al gato de Rosa Luxemburgo: Y tú, Mimí, tan pródigo en vidas, dinos, antes de que la nuestra se consume, ¿que opinas?

\section{BIBLIOGRAFÍA}

Abellán, Joaquín(1992), «El pensamiento político de Max Weber», Historia de la teoría política,(4), (Edc. Fernando Vallespín), Madrid, Alianza Editorial, 532 págs., págs 440-468.

Aron, Raymond (1967), Les étapes de la pensée sociologique, Paris, Éditions Gallimard, 663 págs. (existe trad. cast.).

Aron, Raymond (1965), Ensayo sobre las libertades (trad. cast. Ricardo Ciudad Andreu), Madrid, Alianza Editorial, 1966 (3. ${ }^{\mathrm{a}}$ ed. 1974), 235 págs.

Beetham, David (1974), Max Weber y la teoría política moderna (trad. cast. Fernando Pérez Cebrian), Madrid, Centro de Estudios Constitucionales, 1979, 459 págs.

De Beaumont, Gustave (1831-1832), Lettres d'Amérique 1831-1832 (textos anotados por A. Jardin y G. W. Pierson), París, Presses Universitaires de France, 1973, 221 págs.

Birnbaum, Pierre (1970), Sociologie de Tocqueville, París, Presses Universitaires de France, 159 págs.

Díez del Corral, Luis (1989), El pensamiento de Tocqueville, Madrid, Alianza Universidad, 402 págs.

Furet, François (1991), «L'importance de Tocqueville aujourd'hui», L'actualité de Tocqueville, Cahiers de Philosophie politique et juridique, n. ${ }^{\circ} 19$, Caen, 180 págs.

Furet, François (1984), «Naissance d'un paradigme: Tocqueville et le voyage en Amérique (1825-1831)», Annales, n. ${ }^{\circ}$ 2, Marzo-Abril de 1984, págs. 225-425.

Giddens, Anthony (1972), Política y Sociología en Max Weber (trad. cast. Andrés Linares), Madrid, Alianza Editorial, 1976, 98 págs.

González García, José M. (1989), La máquina burocrática (Afinidades electivas entre Max Weber y Kafka), Madrid, Editorial Visor, 222 págs.

Jaspers, Karl (1920, 1932), Conferencias y ensayos sobre historia de la filosofía, Madrid, Editorial Gredos, 1972, 459 págs.

Lamberti, Jean-Claude (1983), Tocqueville et les deux démocraties, París, Presses Universitaires de France, 325 págs.

Marx, Carlos; Engels, Federico, Obras escogidas I, II, Madrid, Akal Editor, 1975, 748 págs., 571 págs. 
Lindholm, Charles (1990), Carisma (trad. cast. Carlos Gardini), Barcelona, Editorial Gedisa, 1992, 303 págs.

Luxemburgo, Rosa, Huelga de masas, partido y sindicatos (trad. cast. José Aricó, Nora Rosenfeld), Argentina España, Siglo XXI, 1970 (2ª 1974), III pp..

Macpherson, C. B. (1966), La realidad democrática (trad. cast. Carlos Sánchez-Rodrigo), Barcelona, Fontanella, 1968, 89 págs.

Macpherson, C. B. (1976),La democracia liberal y su época (trad. cast. Fernando Santos Fontela), Madrid, Alianza Editorial, 1981, 150 págs.

Manent, Pierre (1993),Tocqueville et la nature de la démocratie, París, Julliard, 1982, Fayard, 1993, 181 págs.

Mill, John Stuart, Sobre la libertad (Prólogo de Isaiah Berlin, trad. cast. Pablo de Azcárete), Madrid, Alianza Editorial, 1970, $3^{\text {a }}$. ed. 1981, 207 págs.

Mill, John Stuart, Sobre la libertad y comentarios a Tocqueville (edc. Dalmacio Negro Pavón, trad. cast. Cristina García Gay), Madrid, Espase Calpe, 1991, 388 págs.

Mill, John Stuart (1979), Capítulos sobre el socialismo y otros ensayos (Introduc. trad. cast. y notas Dalmacio Negro Pavón), Madrid, Aguilar, 174 págs.

Mill, John Stuart (1873), Autobiografía (trad. cast. Carlos Mellizo), Madrid, Alianza Editorial, 1986, 290 págs.

Mill, John Stuart, Del gobierno representativo (Presentación de Dalmacio Negro Pavón, trad. cast. Marta C: C. de Iturbe), Madrid, Técnos, 1985, 215 págs.

Mill, John Stuart (1865), Augusto Comte y el positivismo, Buenos Aires, Aguilar, 1972.

Mill, John Stuart, La Révolution française de 1848 et ses détracteurs, Colección de Folletos del Ateneo de Madrid.

Mitzman, Arthur (1969), La jaula de hierro. Una interpretación histórica de Max Weber (trad. cast. Ángel Sánchez Pascual y María Dolores Castro Lobera), Madrid, Alianza Editorial, 1976, 288 págs.

Mommsen, Wolfgang J. (1959), Max Weber and German politics 1890-1920 (trad. americana. Michael S. Steinberg), Chicago y Londres, The University of Chicago Press, 1984, 498 págs.

Mommsen, Wolfgang (1965), «La sociología política de Max Weber y su filosofía de la historia», Presencia de Max Weber (Talcot Parsons y otros), Buenos Aires, Ediciones de Nueva Visión, 1971, 265 págs.

Mommsen, Wolfgang (1974), Max Weber. Sociedad, política e historia (Versión castellana de Ernesto Garzón Valdés), Editorial Laia, 1981, 333 págs.

Schleifer, James T. (1980), Cómo nació «La democracia en América» de Tocqueville (trad. cast. Rodrigo Ruza), Méjico, Fondo de Cultura Económica, 1984, 426 págs.

Schmitt, Carl (1950), Ex captivitate salus (trad. cast. Ánima Schrnitt de Otero), Santiago de Compostela, Porto y Cia. editores, 1960, 100 págs.

Tocqueville, Alexis de; Mill, John Stuart, Correspondence anglaise, Tomo VI, volumen I, París, Gallimard, 1991 (existe trad. cast.). 
Tocqueville, Alexis de, De la Démocratie en Amérique, Souvenirs, L'Ancien Régime et la Révolution (Introduc. y notas Jean-Claude Lamberti y Françoise Mélonio), Paris, Robert Laffont, 1986, 1178 págs. (existe trad. cast. de cada una de las obras).

Tocqueville, Alexis de, OEuvres I (Edc. dirigida por André Jardin, colaboración de Françoise Mélonio y Lise Queffélec), París, Bibliothèque de la Pléiade, 1991, 1675 págs.

Valdecantos, Antonio (1992), «Argumentos weberianos», Claves de Razón Práctica, 27.

Weber, Max, El político y el científico (Introduc. Raymond Aron; trad. cast. Francisco Rubio Llorente), Madrid, Alianza Editorial, 1967 ( $7^{\mathrm{a}}$ ed. 1981), 231 pp..

Weber, Max, Escritos Políticos (Edc. Joaquín Abellán), Madrid, Alianza Editorial, 1991, 370 págs. 
